\title{
Online System for Monitoring and Analysis of the Operation of a Small Photovoltaic Plant
}

\author{
Nikolay Hristov ${ }^{1}$, Maik Streblau ${ }^{2}$ and Tatyana Dimova ${ }^{2}$ \\ 1 - 3K AD, Varna, Asparuhovo 9003, Malka Chayka \\ 2 - Technical University of Varna, Department of Electrical Engineering and Electro technologies, 9010, 1 Studentska Street, Varna, Bul- \\ garia \\ Corresponding author contact: streblaudtu-varna.bg
}

\begin{abstract}
This article proposes an integrated system for monitoring and analysis of the operation of a small photovoltaic plant with the possibility of remote access via the Internet. The system has been built on the territory of Varna Technical University and is based on a mini computer Raspberry P $i$ $3 B+$ using a Linux operating system. The monitoring is performed by keeping track of the environmental parameters and the input-output parameters of the photovoltaic inverter. Data are presented for a period of three months: October 1, 2020 to December 31, 2020. The results are visualized by appropriate graphs, demonstrating the change in the observed indicators, both for the entire specified period and for a randomly selected day.
\end{abstract}

Keywords: solar energy, monitoring system, irradiation, online system, photovoltaic system

\section{$1 \quad$ Introduction}

Climate change, rising fossil fuel prices and the need to ensure energy diversification and security in recent years have led to increased interest in renewable energy sources (Solaun \& Cerda, 2019). Most of these sources have an uneven distribution throughout the day, month or year (Misak \& Prokop, 2016), which poses a serious challenge for their integration into the electricity grid (Oskouei \& Mohammadi-Ivatloo, 2020). Given this feature, energy production forecasting is performed by taking into account the observations both on the initial parameters of electricity, immediately before its transmission to the electricity grid (Inman et al., 2013), and on the environmental parameters related to energy conversion of the respective renewable energy source. In view of the above, many photovoltaic plants that convert solar energy, as well as systems that convert energy from another type of renewable source, require the use of a monitoring and data collection system (Drews et al., 2007), (Farihah et al., 2015), (Tina \& Grasso, 2014), (Madeti \& Singh, 2017).

The purpose of this article is to present an integrated online system for monitoring the parameters of a photovoltaic system using the Sunny Sensor Box measuring system and the Sunny Boy grid- inverter.

\section{$2 \quad$ Monitoring System}

A monitoring system has been set up in order to monitor the parameters of the environment and the electrical parameters of the energy obtained through a small photovoltaic plant. Access to the data is provided through remote access via the Internet. The photovoltaic plant and the adjacent monitoring system are located on the lower building of the Faculty of Electrical Engineering at the Technical University of Varna. The location of the facility has the following GPS coordinates: Latitude $43.21^{\circ} \mathrm{N}$, Longitude $27.90^{\circ} \mathrm{E}$, Altitude $35 \mathrm{~m}$.

Fig. 1 shows a diagram of the topology of the monitoring system. It consists of different types of devices using various communication protocols, and the obtained data are processed via a mini computer Raspberry Pi 3B + with Linux operating system. 


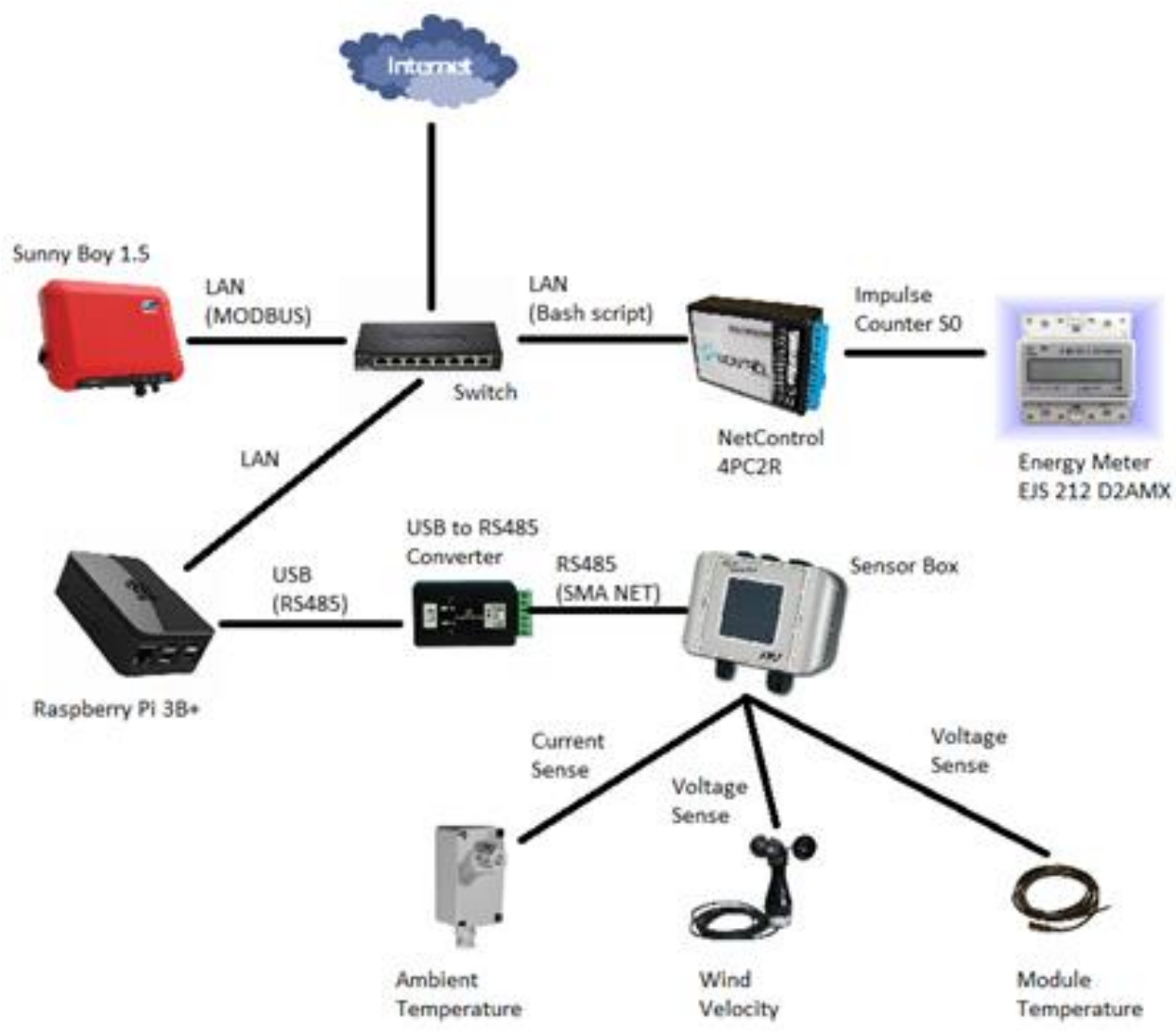

Fig. 1. Monitoring system block diagram.

The main components of which the system is composed are the following: measuring device Sunny Sensor Box, electricity meter for measuring the generated electricity, grid-tie inverter and minicomputer for data processing.

Below are presented the technical parameters of the measuring system Sunny Sensor Box - Fig. 2:

- Measuring System Sunny Sensor Box:

- Communication with Data Logger through RS485;

- Interface - Power Injector;

- Maximum communication distance through RS485 - $1200 \mathrm{~m}$;

- $\quad$ Power Supply through Power Injector - Integrated in USB converter to RS485;

- Input Voltage - 5 V DC Voltage;

- Consumption less than $1 \mathrm{~W}$;

- Solar Radiation Sensor:

- Cell - Amorphous Silicon

- Measuring Range $-0 \div 1500 \mathrm{~W} / \mathrm{m}^{2}$

- Resolution $-1 \mathrm{~W} / \mathrm{m}^{2}$

- Measurement Accuracy - +/- 8\%

- $\quad$ Anemometer -

- Measuring Range - to $40 \mathrm{~m} / \mathrm{s}$

- Resolution $-0.4 \mathrm{~m} / \mathrm{s}$

- Accuracy - $\pm 0,5 \%$

- Maximum Load - 60 m/s

- Temperature Sensor

- $\quad$ Thermosensitive Element - PT100;

- Measuring Range - $-30 \div+80^{\circ} \mathrm{C}$; 
- Accuracy $- \pm 0.7^{\circ} \mathrm{C}$

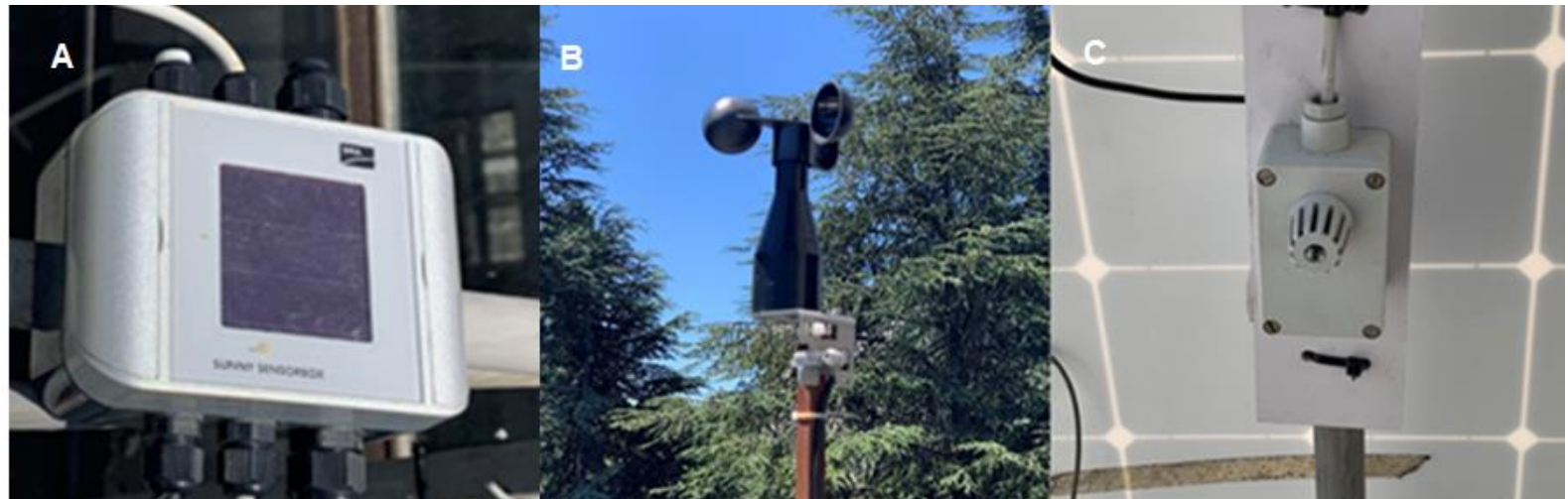

Fig. 2. Measuring System Sunny Sensor Box - A - Solar Radiation Sensor; B- Anemometer; C - Temperature Sensor; tics:

The Photovoltaic Inverter Sunny Boy 1.5, is presented in Fig. 3a and has the following characteris-

- Maximum DC Voltage - 600V;

- $\quad$ MPPT Voltage - from $160 \mathrm{~V}$ to $500 \mathrm{~V}$;

- Maximum DC Current - 10A;

- Module Maximum Short Circuit Current: 18A;

- Rated AC Voltage - 230V;

- Rated Active Power-1500W;

- Rated Apparent Power-1500VA;

- Rated Frequency $-50 \mathrm{~Hz}$;

- Maximum Output Current - 7A;

- Possibility of Adjustment of $\cos \varphi$

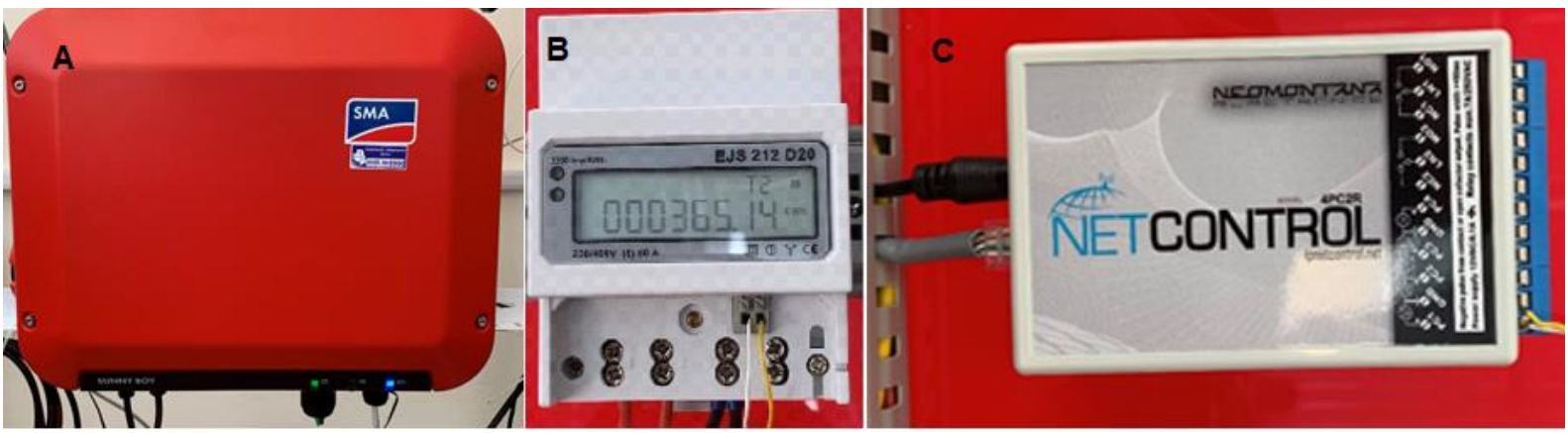

Fig.3. Grid inverter and и electricity meter device:

A - Grid inverter Sunny Boy 1.5; B - Electricity meter EJS 212 D20; $\mathrm{C}$ - Pulse counter NET Control.

The electricity meter used to read the electric power produced by the photovoltaic inverter is model EJS 212 D20 as shown in Fig. 3b, and has the following characteristics:

- Accuracy - 1;

- Rated Voltage - $230 \mathrm{~V}$;

- Base Current - 5 A;

- Maximum Current - $60 \mathrm{~A}$;

- Phase - 1;

- Start Current - < $20 \mathrm{~mA}$;

- Constant - $3200 \mathrm{imp} / \mathrm{kWh}$;

- Impulse Output - $3200 \mathrm{imp} / \mathrm{kWh}$. 
The reading of the electrical energy from the single-phase electricity meter is performed by a pulse counter (Fig. 3c) with the following characteristics:

- 4 Inputs for Counting Pulses;

- Commutation to 2 Load Devices to 7A/220VAC.

- 10 BASE-T Ethernet Interface (without Cross Over AutoDetect);

- Protocols ARP / DHCP / ICMP / TCP / IP / SNMP / TFTP Client / WEB Server

- 802.1q VLAN

- SNMPv1 Protocol;

- Generation of SNMP-Trap Messages when Changing Inputs;

- Generation of Output Signals when Changing the Analog Inputs

- Access via WEB to all parameters and functions of the module;

- TFTP Client for System Software Update.

The core of the monitoring system is built through a third-generation single-board computer - Raspberry Pi 3 Model B +. This computer contains (Fig.4):

- Processor - Broadcom BCM2837B0, Cortex-A53 (ARMv8) 64-bit SoC @ 1.4GHz

- RAM - 1GB LPDDR2 SDRAM

- Wi-Fi Communication - $2.4 \mathrm{GHz}$ and $5 \mathrm{GHz}$ IEEE $802.11 \mathrm{~b} / \mathrm{g} / \mathrm{n} / \mathrm{ac}$ wireless LAN, Bluetooth 4.2, BLE

- Ethernet Communication - Gigabit Ethernet over USB 2.0 (Maximum Throughput 300 Mbps)

- 40 pins controllable Input / Output Communication

- Video Output - HDMI

- 4 USB 2.0 ports

- Input for Micro SD Card

- Voltage Supply 5.1V/2.5A

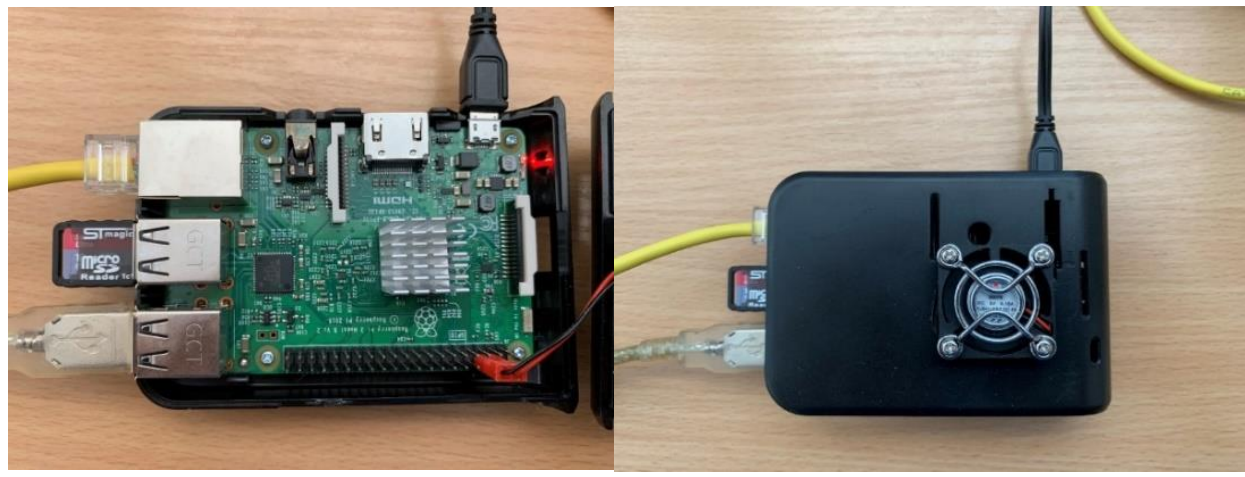

Fig. 4. Mini PC Raspberry Pi 3 Model B+.

For communication of the minicomputer with the measuring system Sunny Sensor Box, a USB to RS485 converter with FT232RL chip is used having the following technical parameters

- Integrated USB Resistors;

- $\quad$ Data Transfer from 300 baud to 3 Mbaud;

- DC / DC Converter 5V/12V for Sensors Supply.

The communication between the Raspberry Pi 3B+ minicomputer and the SMA Sunny Sensor Box measuring system is carried out by a program code realized through the $\mathrm{C}$ programming language, using an existing library (YASDI) for the SMA NET protocol as well as an external CURL library to send the program data to the database. The grid-tie inverter Sunny Boy 1.5 supports the MODBUS communication protocol and in particular the SunSpec photovoltaic inverter protocol. SunSpec MODBUS is an open standard that defines common parameters and settings for monitoring and control of decentralized 
energy resource - DER systems. SunSpec Modbus is specified in the US National Standard (IEEE Std 1547, 2018). Its characteristics and benefits include interoperability with many manufacturers of solar inverters, energy storage de-vices, trackers, electricity meters and other DER devices. Semantically identical and fully interoperable with the communication protocols IEEE 2030.5 (IEEE Std 2030.5, 2018) and IEEE 1815 (IEEE Std 1815, 2015), thus ensuring a high signal-to-noise ratio for DER grids.

The Grafana platform (Salituro, 2020) is used to display the data in graphical form, and the webbased Webmin panel (Ling, 2014) is used to administer the minicomputer as well as the standard Linux console access SSH. All information is collected in the InfluxDB database.

\section{Results}

The implemented monitoring system has been functioning since October 1, 2020. The data presented are for the period from 1 October, 2020 to 31 December, 2020. Relationships are specified for solar radiation, wind speed, ambient temperature, and also data on the parameters of the electrical energy obtained at the output of the inverter.

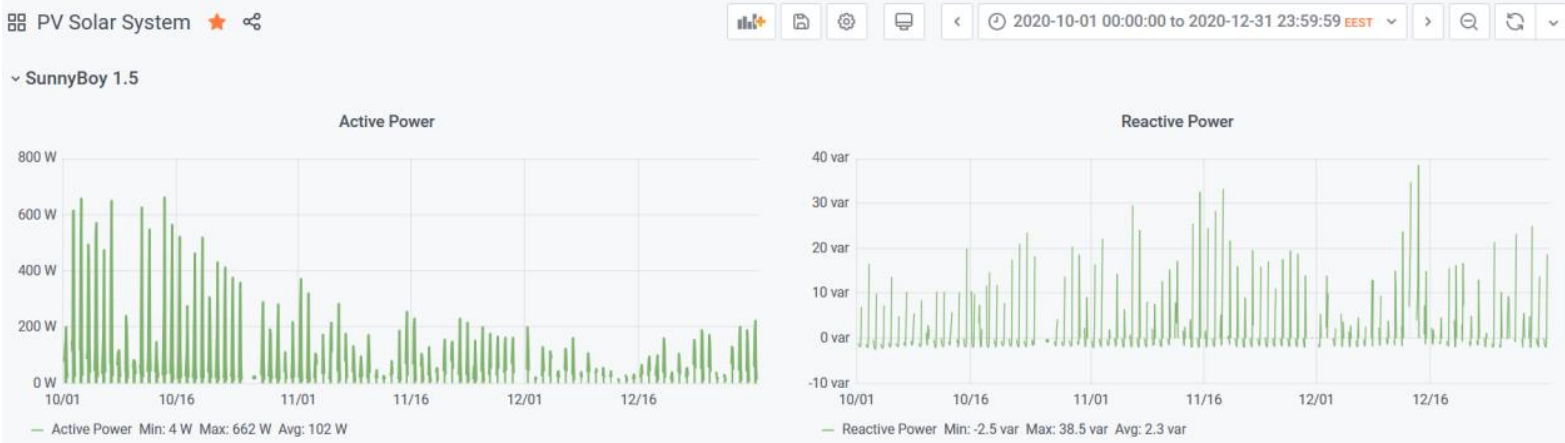

Fig. 5. Active and reactive power values during from 1 October, 2020 to 31 December, 2020.
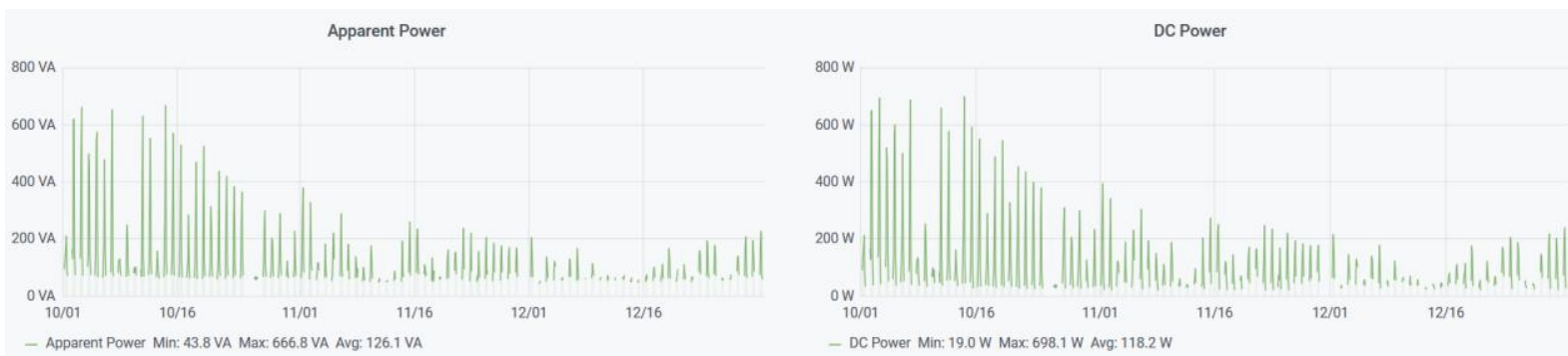

Fig. 6. Apparent and DC power values during from 1 October, 2020 to 31 December, 2020.

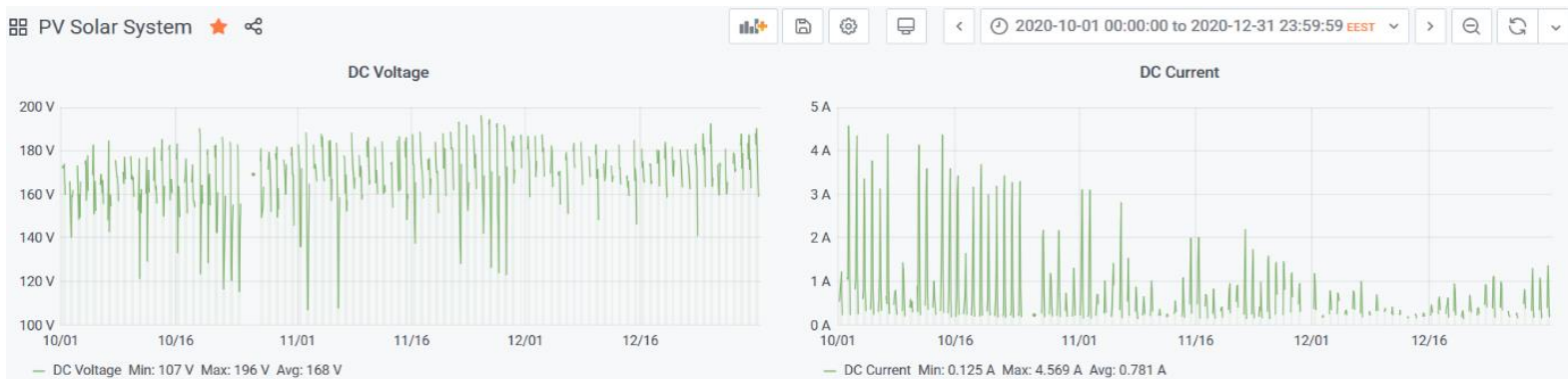

Fig. 7. DC voltage and DC current values from 1 October, 2020 to 31 December, 2020. 


\section{ISSN 2603-316X (Online)}

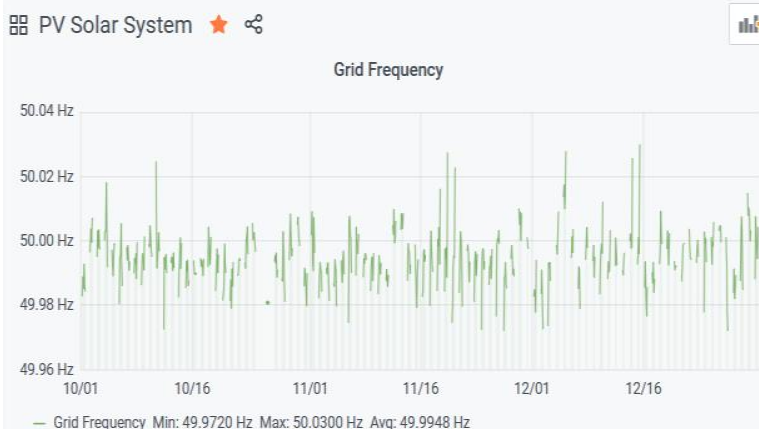

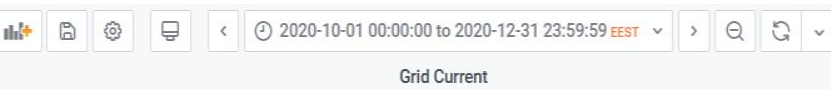

Fig. 8. Grid frequency and current values from 1 October, 2020 to 31 December, 2020.
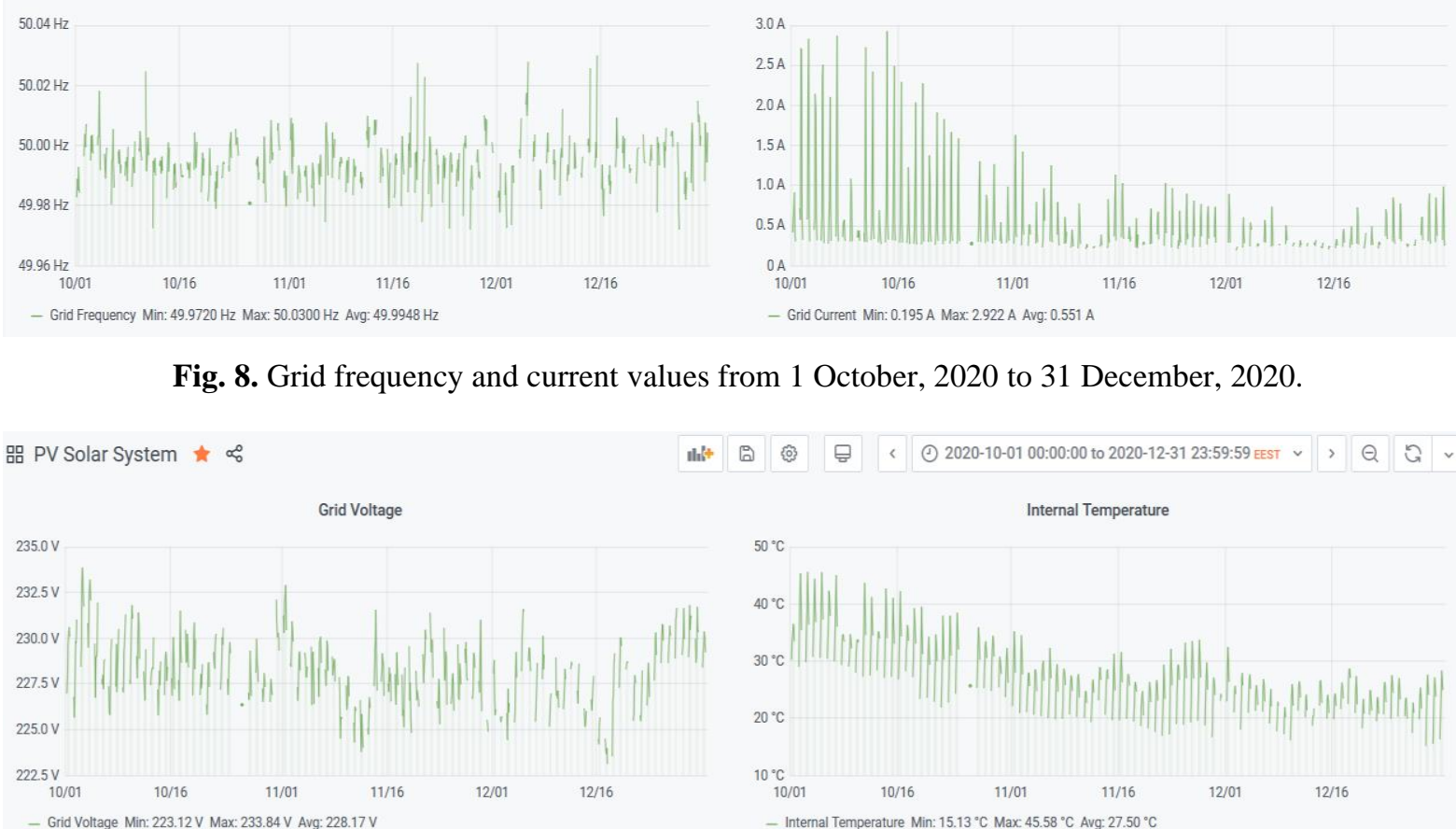

Grid Current Min:0195 A Max 2922 A Avg:0.551 A

Fig. 9. Grid voltage and inverter temperature values from 1 October, 2020 to 31 December, 2020.
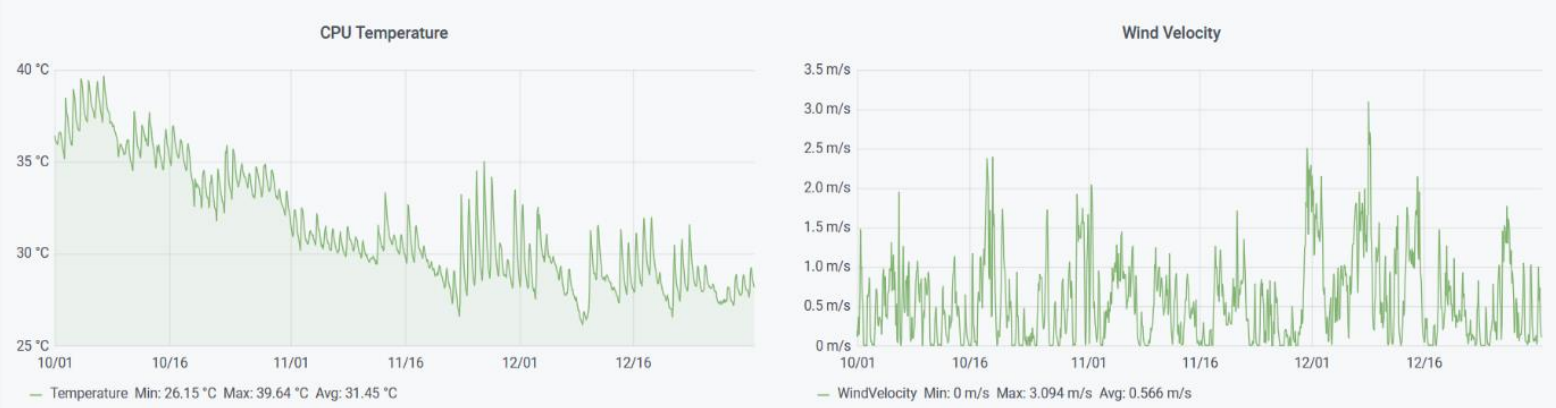

Fig. 10. CPU temperature and wind velocity values from 1 October, 2020 to 31 December, 2020.
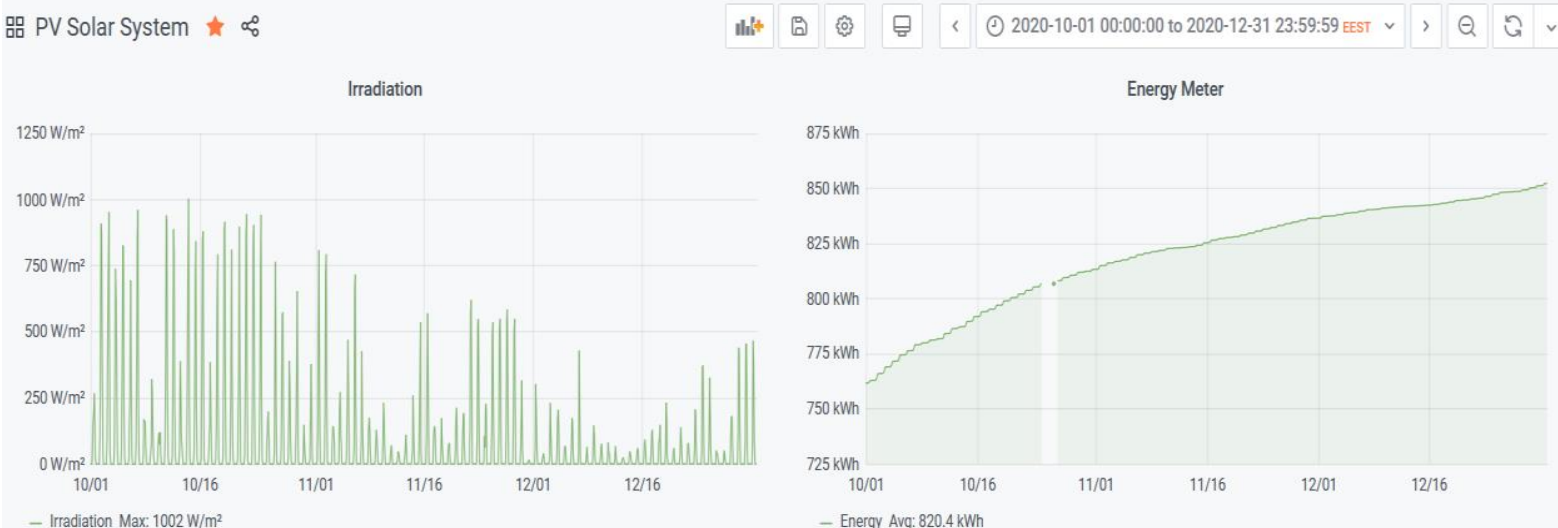

Fig. 11. Irradiation and energy values from 1 October, 2020 to 31 December, 2020. 

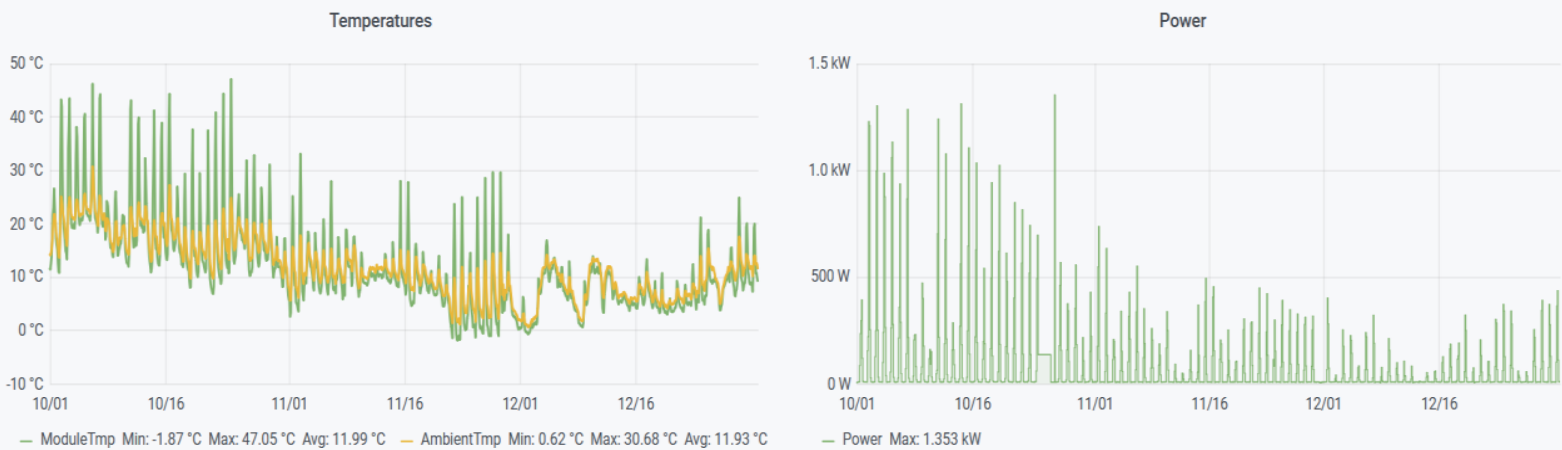

Fig. 12. Ambient and module temperature, and average one hours power values from 1 October, 2020 to $31 \mathrm{De}-$ cember, 2020.

The figures below show graphs for a randomly selected day in the period 01 October, 2020 to 31 December, 2020. The same indicators have been reported as in the graphs presented.
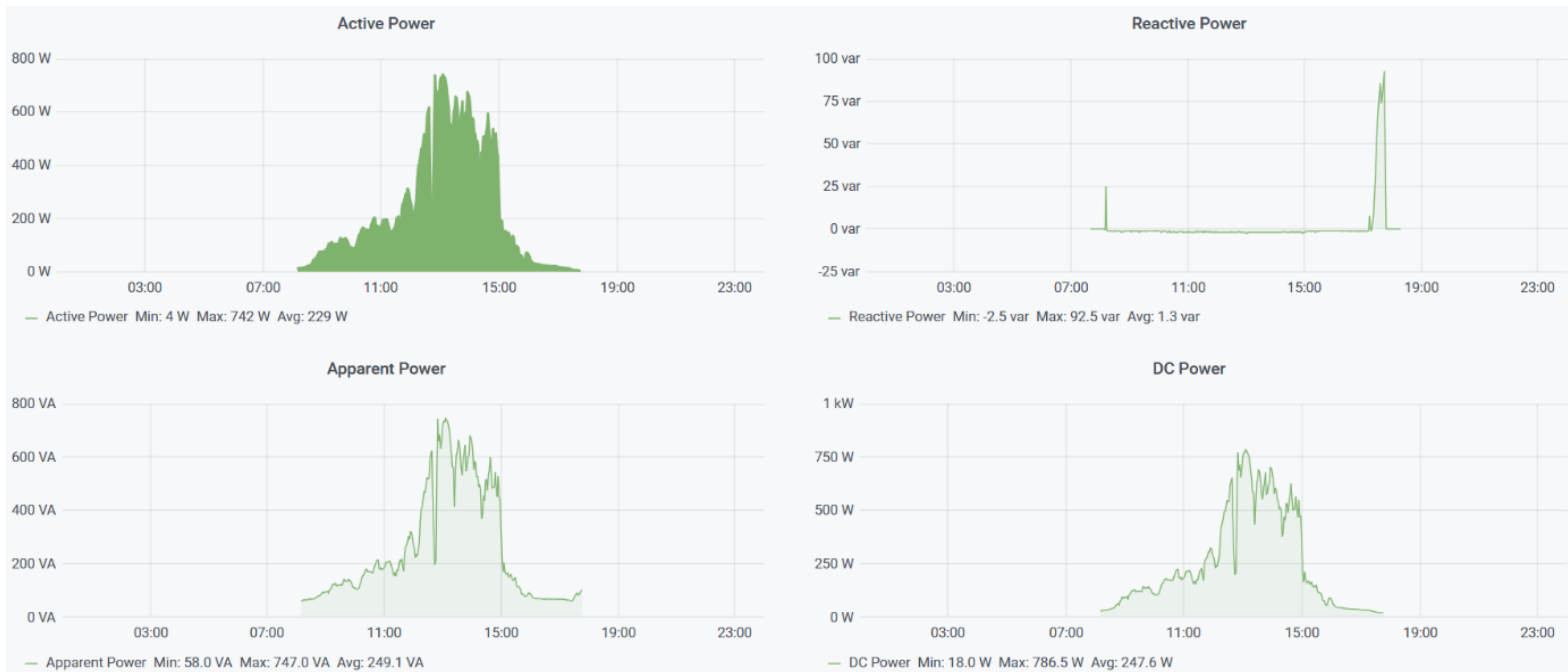

Fig. 13. Power values for 15 October 2020.
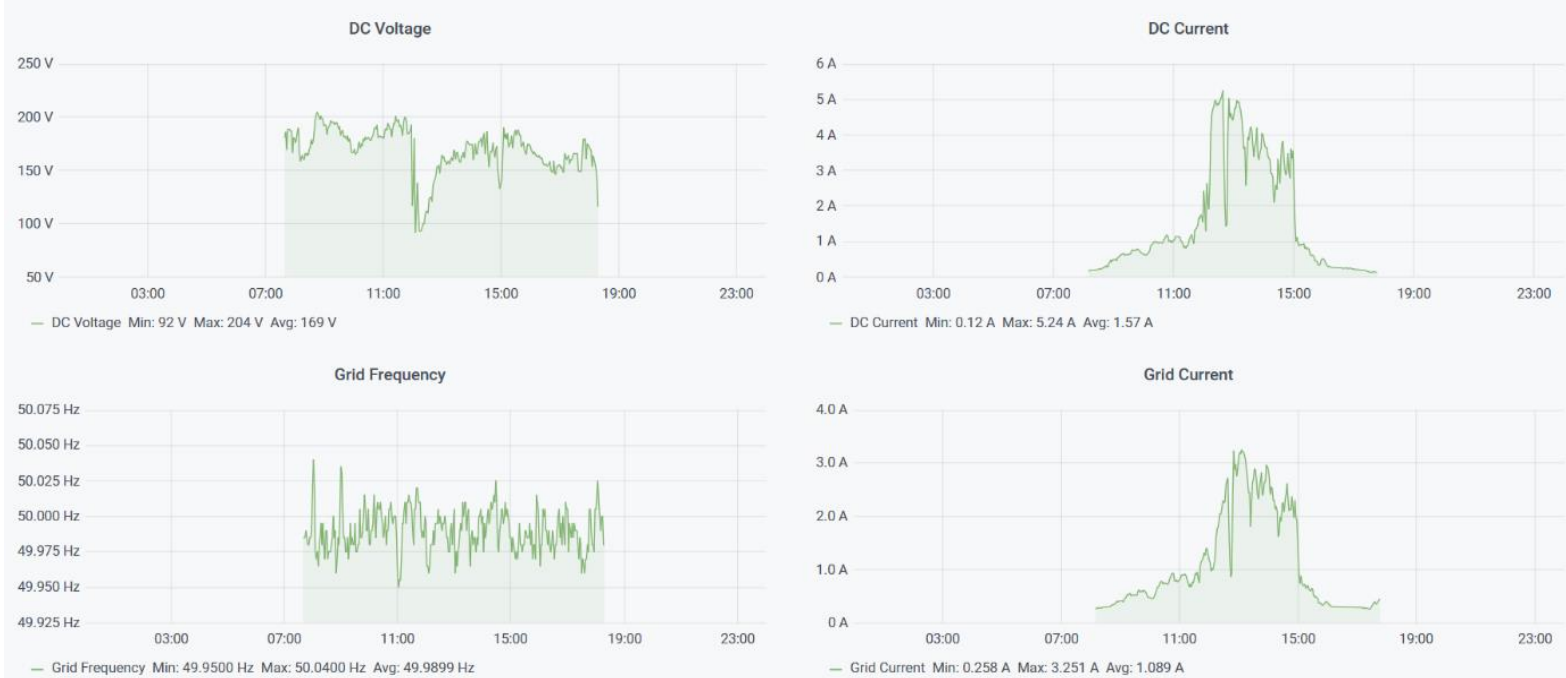

Fig. 14. DC voltage, DC current, grid frequency and grid current values for 15 October 2020. 

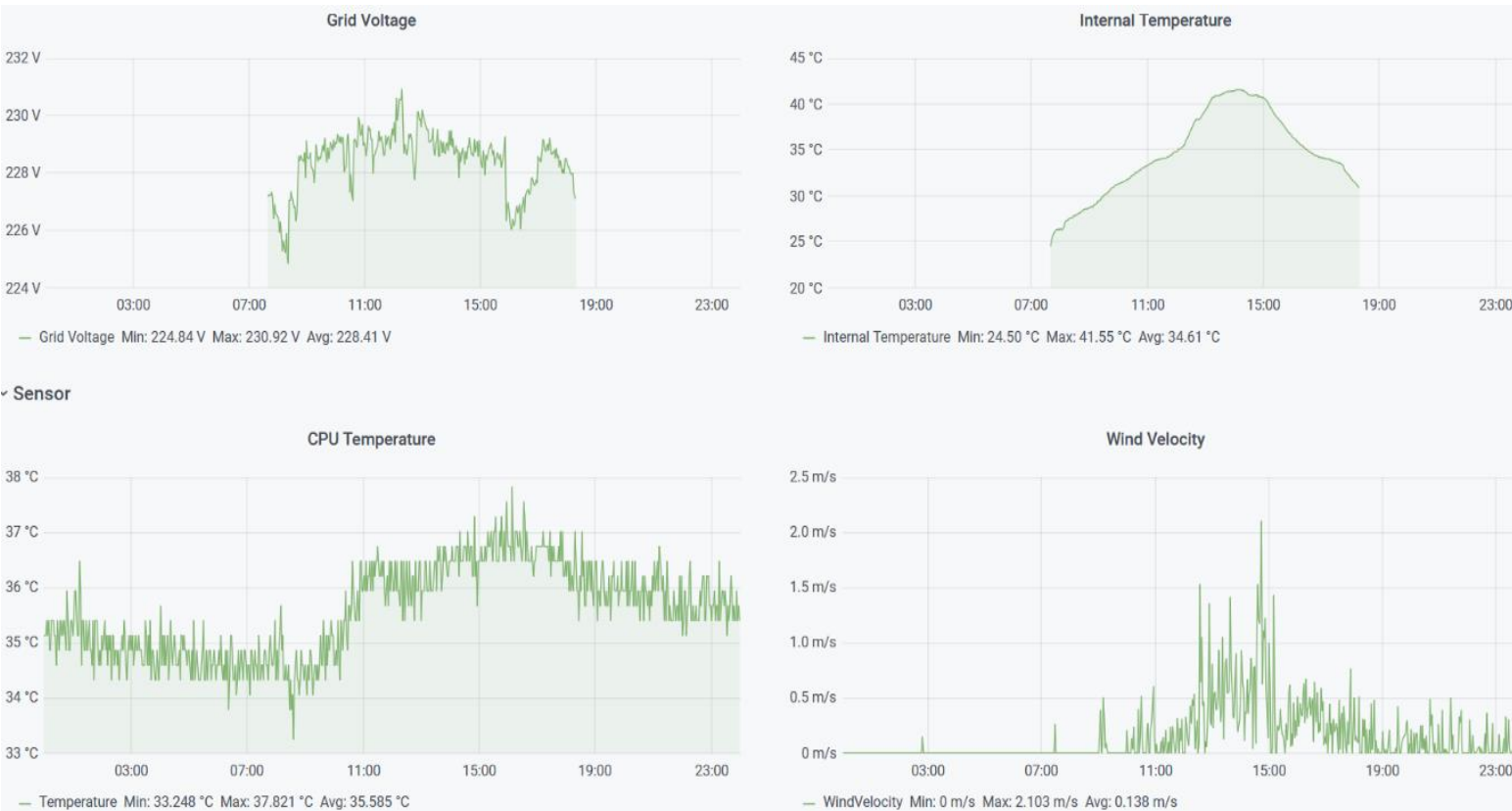

Fig. 15. Grid voltage, inverter temperature, CPU temperature and wind velocity values for 15 October 2020.
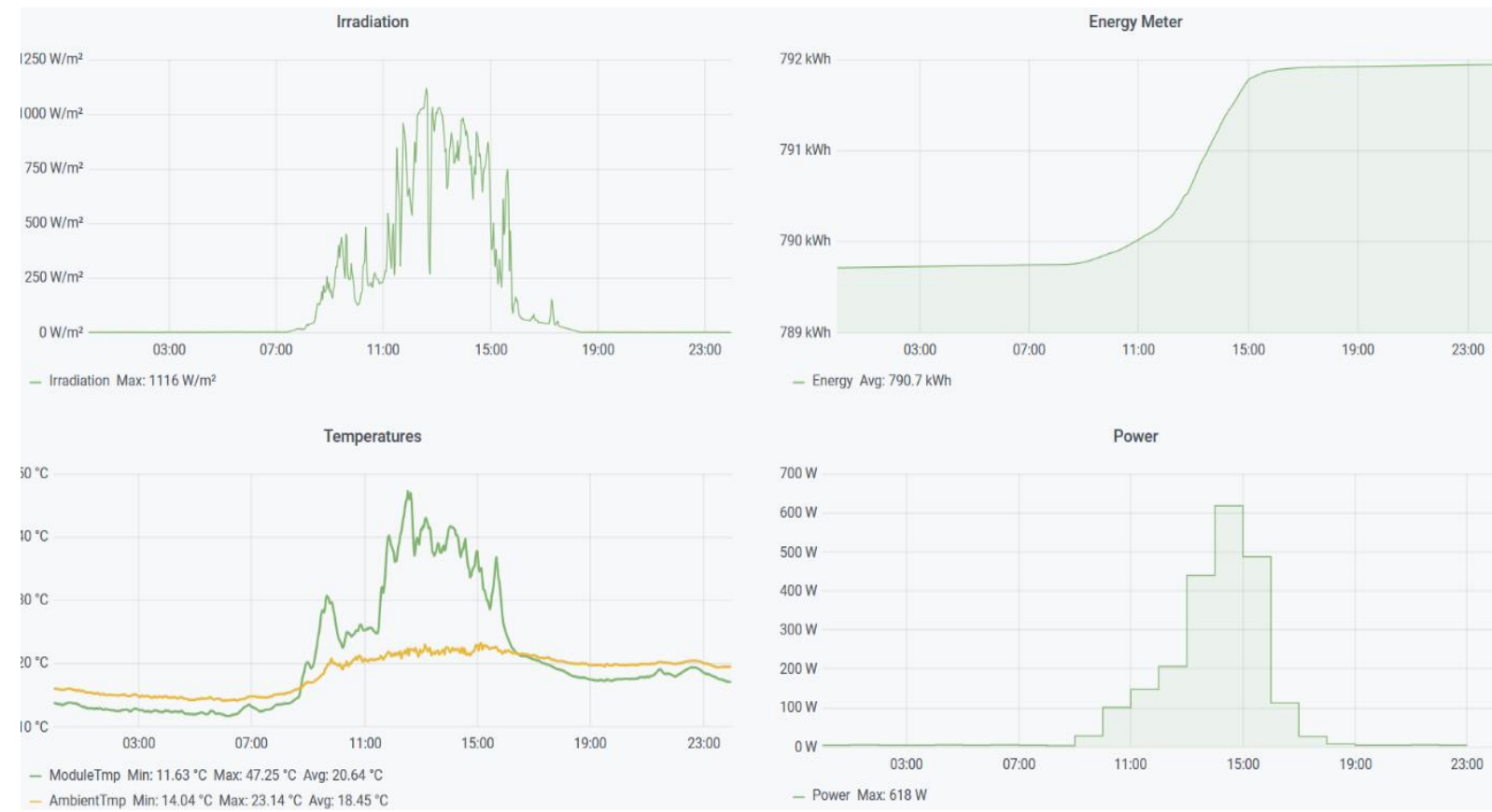

Fig. 16. Irradiation, ambient and module temperature, energy, one hours power, and wind velocity values for 15 October 2020.

\section{Conclusion}

The monitoring system is an integral part of any photovoltaic plant. It enables a quick and easy identification of a problem, and the availability of archival data helps to ensure quality analysis and allows accurate diagnosis of the condition of the photovoltaic plant through remote access.

The analysis of the obtained results shows stable operation of the photovoltaic system, as the temperature during operation of the inverter remains relatively low, even at maximum load. The reactive power during operation of the inverter is close to zero, and the grid frequency is stable and meets the tolerances specified in the standards. 
The presented monitoring system allows it to be implemented to photovoltaic systems not only of a grid type but also of an autonomous or hybrid type.

To ensure the completeness of the research, it is necessary to collect data during one year at least. This would allow the data to be integrated into software products for modelling and analysis of the operation of photovoltaic systems for the respective location where the research is carried out.

\section{Acknowledgments}

This paper is developed in the frames of project „Design and investigation of stand-alone photovoltaic system", № КД1/2020.

\section{References}

Inman, R., H. Pedro, C. Coimbra. (2013). Solar forecasting methods for renewable energy integration. Journal of Progress in Energy and Combustion Science, 39, pp. 535 - 576. https://doi.org/10.1016/j.pecs.2013.06.002.

Ling, A. (2014). Webmin \& Virtualmin: The Open source alternative to Cpanel. eBook.

Misak, S., L. Prokop. (2016). Renewable energy sources - Overview. Springer Link. https://doi.org/10.1007/978-3-319-43412-4_1.

Madeti, S., S. Singh. (January 2017). Monitoring system for photovoltaic plants: A review. Journal of Renewable and Sustainable Energy Reviews, Vol. 67, pp. 1180 - 1207. https://doi.org/10.1016/j.rser.2016.09.088.

Tina, G., A. Grasso. (2014). Remote monitoring system for stand - alone photovoltaics power plants: The case study of a PV - powered outdoor refrigerator. Journal of Energy Conversion and Management, 78, pp. 862 - 871. https://doi.org/10.1016/j.enconman.2013.08.065.

Drews, A., A. C. Keizer, H. G. Beyer, E. Lorenz, J. Betcke, W. G. van Sark, W. Heydenreich, E. Wiemken, S. Stettler, P. Toggweiler, S. Bofinger, M. Schnedier, G. Heilscher, D. Heinemann. (2007). Monitoring and remote failure detection of grid-connected PV systems based on satellite observations, Journal of Solar Energy, 81, pp. $548 \quad-564$. https://doi.org/10.1016/j.solener.2006.06.019.

Farihah, Sh., N. Rahim, H. W. Ping. (2015) Zigbee-based data acquisition systemfor online monitoring of grid-connected photovoltaic, Journal of Expert System with Applications, 42, pp. 1730-1742. https://doi.org/10.1016/j.eswa.2014.10.007.

Oskouei, M., B. Mohammadi-Ivatloo. (2020). Integration of renewable energy sources into the power grid through power factory. Springer Link

Salituro, E. (2020). Learn Grafana 7.0: A beginner's guide to getting well versed in analytic, interactive dashboards, and monitoring. Packt Publishing

Solaun, K., E. Cerda. (2019). Climate change impacts on renewable energy generation: A review of quantitative projections, Journal Renewable and Sustainable Energy Reviews, 116. https://doi.org/10.1016/j.rser.2019.109415.

IEEE Std 1547. (2018, 6 April). IEEE Standard for interconnection and interoperability of Distributed Energy Resources with Associated Electric Power Systems Interfaces, IEEE, pp.1-138. https://doi.org/10.1109/IEEESTD.2018.8332112. 
IEEE Std 2030.5. (2018, 21 December). IEEE Standard for smart energy profile application protocol, IEEE, pp.1-361. https://doi.org/10.1109/IEEESTD.2018.8608044.

IEEE Std 1815.1 (2016, 16 December). IEEE Standard for exchanging information between networks implementing IEC 61850 and IEEE Std 1815(TM) [Distributed Network Protocol (DNP3)], IEEE, pp.1-358. https://doi.org/10.1109/IEEESTD.2016.7786998. 